\title{
The Place of Neuronal Migration Abnormalities in Child Neurology
}

\author{
Jean Aicardi
}

\begin{abstract}
With the development of modern imaging techniques, disturbances of neuronal migration appear to be a major cause of epilepsy, mental retardation and chronic neurological disability in childhood. Sixty-nine cases are presented, including 46 of diffuse migration abnormalities and 23 of localized dysplasia. Patients with diffuse migration disorders presented with mental retardation, gross motor impairment and severe seizure disorders whereas in those with focal anomalies, epilepsy was the chief complaint. Magnetic resonance imaging, although usually diagnostic of migration disorders often does not allow definition of the pathologic type. Some EEG patterns, such as high amplitude fast rhythms or the theta-delta pattern are highly suggestive. Most cases of abnormal migration are sporadic and probably acquired. Some are due to chromosomal anomalies, especially of chromosome $17 \mathrm{p}$ where a gene for lissencephaly has been mapped. Familial cases occur with both recessive and possibly dominant inheritance. Epilepsy due to migration abnormalities is often intractable. Resection of dysplastic cortex may be effective for localized disease and callosotomy has been proposed for diffuse anomalies.
\end{abstract}

Résumé: La place des anomalies de migration neuronale en neurologie pédiatrique. Suite au développement des techniques modernes d'imagerie, les perturbations de la migration neuronale semblent être une cause majeure d'épilepsie, de retard mental et d'invalidité dans l'enfance. Nous présentons 69 cas, dont 46 cas d'anomalies diffuses de migration et 23 cas de dysplasie localisée. Les patients porteurs de troubles diffus de migration étaient atteints de retard mental, de troubles moteurs marqués et d'épilepsie sévère, alors que chez ceux qui avaient des anomalies focales, l'épilepsie était le problème principal. Bien que l'imagerie par résonance magnétique fournisse habituellement le diagnostic des troubles de migration, souvent elle ne permet pas d'en définir le type anatomopathologique. Certains motifs EEG tels les rythmes rapides de haute amplitude ou les ondes thêta-delta sont hatement suggestifs. La plupart des cas de migration anormale sont sporadiques et probablement acquis. Certains sont dus à des anomalies chromosomiques, spécialement des anomalies du chromosome $17 \mathrm{p}$ où un gène responsable de la lissencéphalie a été localisé. Dans les cas familiaux, l'hérédité peut être récessive ou possiblement dominante. L'épilepsie due à des anomalies de migration est souvent résistante au traitement. La résection du cortex dysplasique peut être efficace quand la maladie est localisée et l'ablation du corps calleux a été proposée lorsque les anomalies sont diffuses.

Can. J. Neurol. Sci. 1994; 21: 185-193

With the development of modern techniques of brain imaging, especially magnetic resonance imaging (MRI), neuronal migration abnormalities, once a pathological curiosity, have come to occupy a first rank place among neurological disorders of childhood.

The neurons that constitute the cortex of the human brain are produced in the ventricular zone by multiplication of precursors that generate daughter cells which leave the cell cycle to become forever postmitotic. These neuroblasts migrate towards the pial surface in successive waves between 12 and 20 weeks conceptional age..$^{1-3}$ Early migrating neurons are located in the deep layers of the cortical plate whereas late-migrating cells are superficial, the so-called inside-out pattern. However, most of the cells of layer I migrate first, forming a loosely organized preplate in the subpial zone. Cells for layers 2-6 form the cortical plate proper that splits the preplate into an outside marginal layer and a deep subplate. Fifty to $90 \%$ of subplate neurons die in the postnatal period. They probably play an important role in pioneering connections between the cortex and subcortical structures. ${ }^{3}$ Migrating cells are directed by glial guides whose processes extend from the ependyma to the pial surface.

From the Hôpital des Enfants Malades, 149 rue de Sèvres, Paris, France.

RECEIVED NOVEMBER 19, 1993. ACCEPTED IN FINAL. FORM MARCH 15, 1994

Presented in part as the Guest Lecture of the Canadian Association for Child Neurology at the 28th Meeting of the Canadian Congress of Neurological Sciences. June 17, 1993, Toronto, Ontario.

Reprint requests to: Jean Aicardi, M.D., The Wolfson Centre, Mecklenburgh Square. London WCIN 2AP England. 
Interactions between migrating neurons and glial guides are complex. They utilize specific adhesion molecules and various, largely unknown, chemical signals that specify their ultimate location and direct their connections. Any interference with this complex process, whether due to an insult to the guides or to neurochemical abnormalities of possible genetic origin can produce neuronal migration defects ${ }^{4}$ of variable types and severity. ${ }^{5}$

The main pathological types of migration abnormalities are shown in Table 1. A full description of those abnormalities is available in several recent reviews. ${ }^{6-11}$

A major difficulty in the study of neuronal migration abnormalities is the use of pathological terms, such as pachygyria or polymicrogyria to designate imaging findings. Although there may be a good correspondence between certain types of imaging data and pathology, such as typical agyria-like images and type 1 lissencephaly, correlations between imaging and neuropathology are far from perfect and have not been established in many published cases. In fact, a thick cortex with apparent paucity of sulci and an abnormal gray-white interface on MRI can be due to agyria, pachygyria or polymicrogyria. " In the latter case, the imaging appearance results from crowding and compression of the multiple small convolutions obliterating the sulci, sometimes with fusion of the molecular layers of adjoining gyri. It is better, therefore, to use the terms agyria-like or pachygyria-like rather than pathological terms when referring to imaging. "In some cases, the undulating appearance of the cortical surface or of the gray-white interface is suggestive of focal or diffuse polymicrogyria and progress in imaging techniques

Table 1. Main pathological types of migration abnormalities.

\section{Major Abnormalities}

I. Type I lissencephaly-agyria: smooth brain, 4-layer cortex with thick layer of arrested heterotopic neurons, resembling a fetal brain at 13 weeks of gestation.

2. Type II lissencephaly (Walker-Warburg syndrome): totally disorganized cortex divided by gliomesenchymal trabeculae into glomeruli with disoriented cells.

3. Pachygyria: few, thick gyri; similar to lissencephaly with less numerous heterotopic neurons.

4. Polymicrogyria: multiple small gyri with 'cauliflower' appearance; 4-layer cortex without heterotopic neurons but paucicellular layer in continuity with normal layers $4-5$. Other types include unlayered microgyria.

5. Localized cortical dysplasia*: absent lamination, anarchic distribution of neurons and glial cells. In one type presence of 'balloon cells' similar to those in tuberous sclerosis.

\section{Minor Abnormalities**}

6. Glioneuronal heterotopias; verrucous cortex, excess cell migration into the molecular layer and meninges.

7. Microdysgenesis: excess number of neurons in molecular layer, irregular thickness of neuronal layers, heterotopic neurons in the outer white matter.

* The term dysplasia is used both in a general sense to designate all developmental cortical abnormalities or in the restricted sense of focalized defect of cortical organization.

** May exist in isolation or be associated with major anomalies. are making such cases more common (Figure 1). Currently, however, the imaging diagnosis of polymicrogyria remains difficult or impossible in many cases. Moreover, several different pathological abnormalities commonly coexist in the same brain. ${ }^{4}$ For these reasons, the term cortical dysplasia is often used in the imaging literature to designate any type of developmental cortical abnormality without reference to pathology. Unfortunately this term is also applied to a particular type of focal cortical developmental anomaly with poor lamination, abnormal location and orientation of neurons and often the presence of abnormal cells reminiscent of the "balloon" cells of tuberous sclerosis but without any gross migration abnormality such as microgyria. In this paper, the term applies to any type of developmental cortical anomaly detectable by MRI.

The classification of neuronal migration abnormalities in this article is entirely based on the results of imaging studies. Pathological anomalies that do not result in abnormal imaging findings, such as microdysgenesis ${ }^{12}$ are not considered, even though they are commonly encountered in isolation or in association with other cortical malformations and they are more commonly found in the brains of patients with epilepsy than in those of controls. ${ }^{13}$

Several patterns of neuronal migration abnormalities have been defined on the basis of MRI.

Diffuse migration defects involving both hemispheres include: 1) agyria-like pattern in which no sulci or only very few sulci are visible; 2) pachygyria-like pattern in which a few shallow sulci limit definable broad, flat gyri both in the anterior and posterior regions of the brain; 3 ) subcortical laminar heterotopias when a ribbon of gray matter is present underneath a more or less normal cortex, separated from the depth of the cortical plate by a thin layer of white matter.

Localized migration abnormalities can be either multiple or single. They are characterized by focal thickening of the cortical plate with an abnormal gyral pattern and an abnormally rectilinear or a blurred border between gray and white matter. Symmetrical areas of migration anomalies can involve the opercular and central regions of both hemispheres.

The focus of this article is on the clinical diagnosis of developmental cortical abnormalities, based on a series of 69 personally observed patients and on review of the pertinent literature. Subcortical migration anomalies such as periventricular heterotopias ${ }^{14,15}$ are not considered except when they are associated with cortical dysplasia (Figure 2). We do not discuss cases of cortical dysplasias due to metabolic diseases such as Zellweger syndrome and other peroxisomal disorders, ${ }^{16}$ glutaric aciduria type $2,{ }^{17}$ nonketotic hyperglycinemia, Menkes disease or pyruvate dehydrogenase deficiency, ${ }^{5}$ nor those of hemimegalencephaly ${ }^{18}$ or of migration disorders that are only a part of complex syndromes such as Aicardi syndrome ${ }^{19}$ or Fukuyama type congenital muscular dystrophy. ${ }^{20}$ Dysplastic cortical lesions that occupy space and are capable of growth, such as dysembryoplastic neuroepithelial tumors, are also excluded.

\section{Personal Series of Patients with Migration Disorders}

Sixty-nine patients with cortical migration anomalies were observed at the Hôpital des Enfants Malades, Paris, between 1980 and 1991. 


\section{Patients with agyria-like pattern}

This pattern was recognized in 21 patients in whom imaging (computed tomography or magnetic resonance) showed, in addition to a smooth cortical surface, a thick cortical plate and absence of operculation with a widely open and verticalized sylvian fissure giving the classical appearance of a figure 8 . The absence of sulci was total in some cases corresponding to grade 1 lissencephaly as defined by Dobyns et al. ${ }^{21}$ and DeRijk van Andel et al. ${ }^{22}$ When a few sulci were present, they were usually
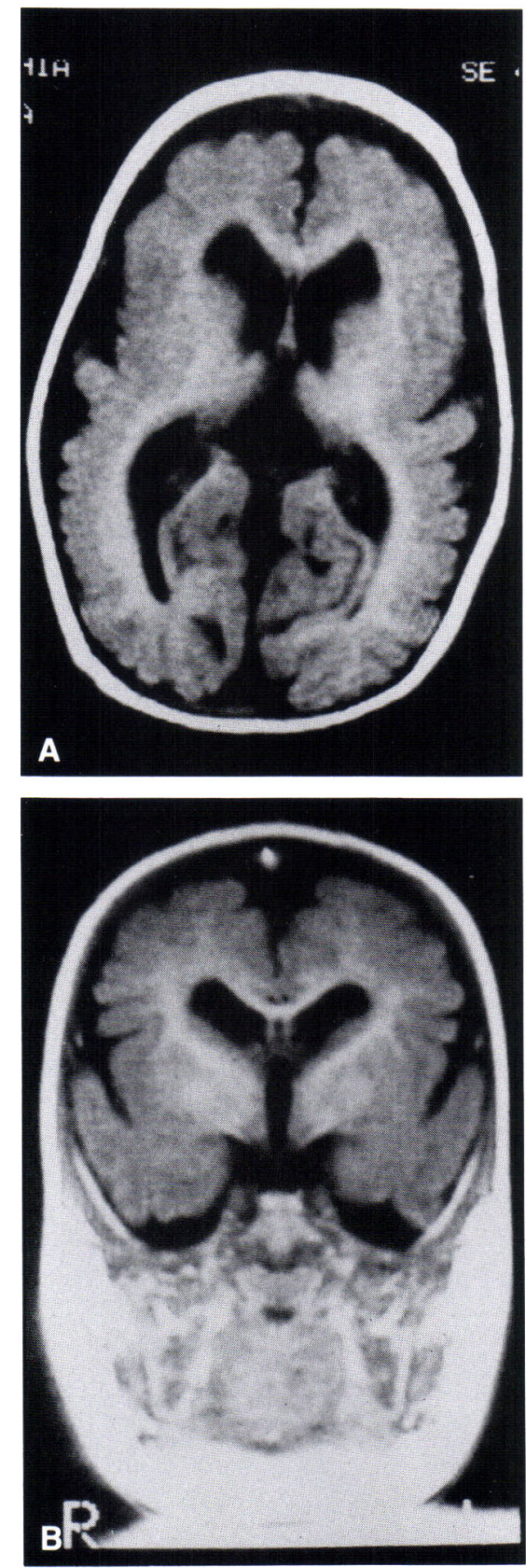

Figure 1: Probable polymicrogyria. T1-weighted MR; a) axial cut; b) coronal cut. The cortex is thickened and the gray-white interface is abnormally straight in both frontal areas as a result of the lack of white matter digitations. In the posterior regions the cortex appears abnormally undulating, suggesting the presence of polymicrogyria rather than pachygyria. seen in the frontal lobes (Figure 3). Such cases correspond to grade 2 and 3 lissencephaly in Dobyns classification. ${ }^{21}$ All affected infants were markedly abnormal from birth and most had major sucking and swallowing difficulties. All had bilateral pyramidal tract signs and many were severely hypotonic. Seventeen infants had early seizures, 14 in the form of infantile spasms. Other types of seizures, notably focal ones, were associated with the spasms in most cases. All children were severely retarded but some could pass simple milestones such as rolling over or even sitting. Microcephaly was present or developed secondarily in 12 infants and was severe in four. No major dysmorphism was present although four infants had a somewhat similar appearance with thin nose and lips and bitemporal hollowing. Only one child had the characteristic feature of the Miller-Dieker syndrome ${ }^{23,24}$ and the diagnosis was confirmed by the finding of a 17 p deletion. ${ }^{25}$

The EEG showed high amplitude $(\geq 200 \mu \mathrm{V})$, fast $(>8-10$ $\mathrm{Hz}$ ) rhythms in 16 cases and high amplitude rhythmic theta and delta activity in 10 children. The latter pattern was interrupted by episodes of non ictal, low amplitude fast rhythms in 4 patients. High amplitude sharp waves were often intermingled and could produce occasional slow spike-wave complexes. Both types of activity were often present in the same patient and even in the same record. They could appear as early as 3 months of age. The fast rhythms tended to disappear early and were rarely seen after 2-3 years of age. Three patients had neither fast nor theta-delta patterns. Their tracings showed only slow background rhythms with occasional spikes or sharp waves.

\section{Patients with pachygyria-like pattern}

A pachygyric appearance of the cortex was found in 15 children. It was characterized by the presence of broad gyri in both the anterior and posterior regions of the brain and by the presence of a thick cortical ribbon with few interdigitations between gray and white matter. The sylvian fissure was abnormally open although less than in lissencephaly cases. In several cases, the surface of the broad gyri appeared undulating, suggesting the probability of polymicrogyria (Figure 4 ) and this was also seen at the gray-white junction in two patients. This appearance could be diffuse or localized. All children had severe to moderate

Table 2. Main types of neuronal migration abnormalities* in 69 patients.

\begin{tabular}{lr} 
Diffuse Dysplasias & \\
\hline -Agyria-like & 21 \\
-Pachygyria-like & 15 \\
-Type 2 lissencephaly** & 7 \\
-subcortical laminar heterotopias & 3
\end{tabular}

\begin{tabular}{lr}
\hline Localized Dysplasias \\
\hline -Bilateral perisylvian and \\
central involvement & 3 \\
-Unilateral focal dysplasias & 20
\end{tabular}

Total 69

* Classified according to imaging appearance.

** Diagnosis based on clincal findings (see text). 
retardation but some could acquire ambulation and even some elements of language (isolated words or 2-word sentences). Twelve patients had seizures of various types. Atonic and tonic seizures, focal attacks, and generalized myoclonic seizures were most common but 4 patients had infantile spasms and several had focal seizures. Eight patients had microcephaly, severe in two. No characteristic dysmorphism was present. Variable EEG abnormalities were encountered: five infants had high-amplitude fast rhythms similar to those in agyric patients; 3 had a theta-delta pattern; 3 more had low amplitude fast rhythms and 7 had only nonspecific EEG abnormalities. Several patterns could be observed in the same patient.

\section{Patients with type 2 lissencephaly (Walker-Warburg syndrome)}

Seven patients had the characteristic features of the WalkerWarburg syndrome that include: 1) major congenital neurological dysfunction, in 5 cases with congenital hydrocephalus; 2) eye abnormalities with retinal dysplasia and variable abnormalities of the anterior chamber such as Peter's anomaly, corneal opacities, synechiae; 3 ) a smooth cortex with a complete absence of lamination and the penetration of gliomesenchymal bundles into the cortex, isolating glomerular or tubular groups of abnormally oriented neurons; 4) agenesis of the cerebellar vermis and severe developmental abnormalities of the hemispheric cortex. Two patients were siblings (brother and sister) born to unrelated healthy parents). Four patients died within the first year of life and only one reached the age of 4 years. Imaging showed prominent hydrocephalus and absence of the cerebellar vermis. The cortex appeared devoid of sulci but interpretation of this finding could be difficult because of extreme distention of the lateral ventricle. No specific EEG abnormality was seen in these patients.

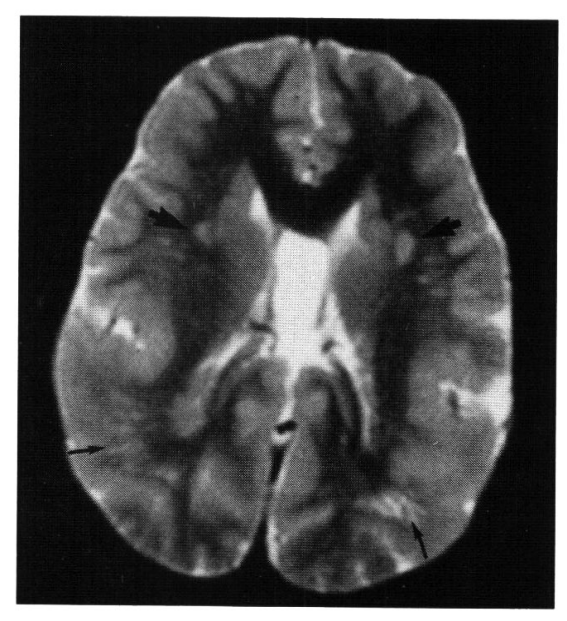

Figure 2: Complex migration disorder. T2-weighted MR. Periventricular heterotopias with associated gyration abnormalities in both parietal regions where the number of sulci is decreased and the cortex appears thickened. There is also dysplasia of the corpus callosum with a high-riding $3 d$ ventricle and rectilinear, abnormally spaced lateral ventricles and multiple subcortical nodular heterotopias (large arrows). Linear streaks of gray matter appearance are visible underneath the cortical plate (small arrows) probably representing clusters of neurons arrested in their migration corridors.

\section{Patients with subcortical laminar heterotopias}

This anomaly, also known as band heterotopia ${ }^{2}$ or the "double cortex" anomaly ${ }^{26-27}$ was found in 3 children. The abnormal subcortical layer was of variable thickness and was universally distributed. The overlying cortex had a normal appearance in all 3 cases. The clinical picture was quite variable. One patient presented at the age of 18 months with metal retardation and a typical picture of the Lennox-Gastaut syndrome. Two other girls ${ }^{26}$ had epilepsy with brief atonic-myoclonic seizures starting respectively at 6 and 13 years of age and mild mental retardation or even only learning difficulties in one. Neurological examination was normal in all three children. The EEG showed typical slow spike-wave discharges in the first patient and nonspecific findings in the others. One girl had bizarre repetitive slow complexes on some of her tracings.

\section{Localized dysplasias}

These were bilateral and roughly symmetrical, involving the insular, opercular and perisylvian areas in 3 girls and were unilateral and apparently isolated in 23 patients.
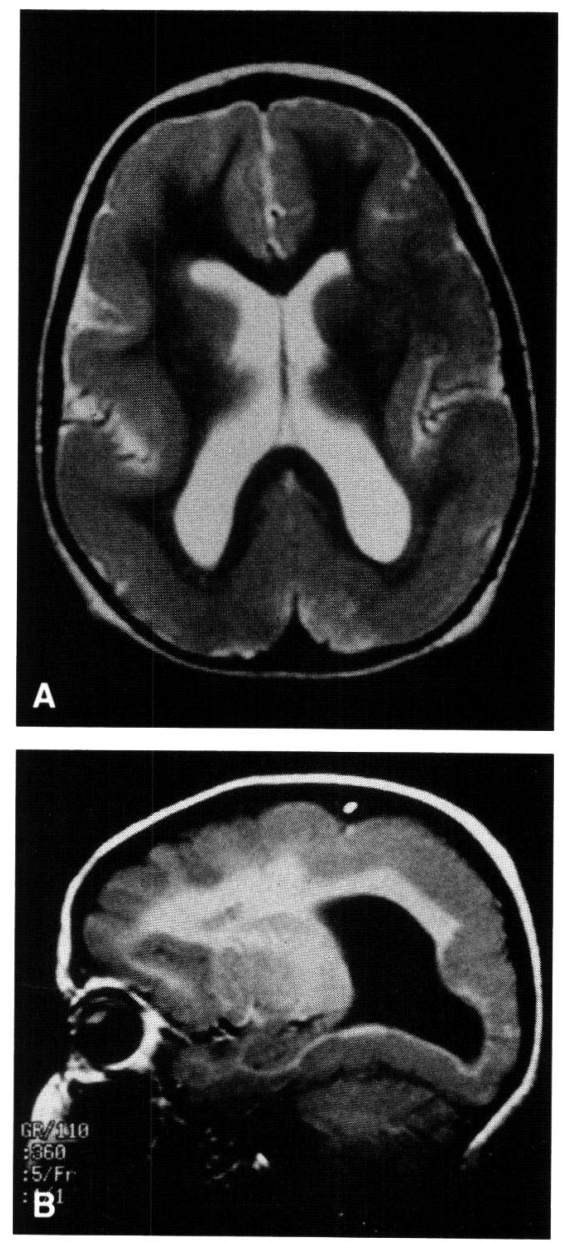

Figure 3: Lissencephaly/pachygyria (grade 2 lissencephaly); a) T2weighted sequence, axial cut; b) T1-weighted sequence sagittal cut. The posterior half of the brain is completely devoid of sulci, consistent with lissencephaly; the anterior half is pachygyric. Note the absence of white-gray interdigitations throughout. The sylvian fissure is not verticalized. 


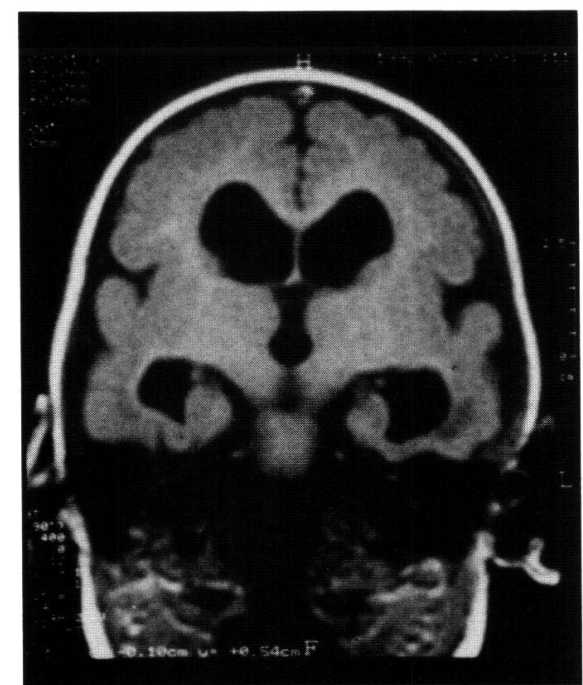

Figure 4: Diffuse pachygyria-like dysplasia; T1-weighted MR, coronal cut. Most of the cortex is thick and smooth. Several sulci are visible in the suprasylvian region bilaterally and there is a faintly visible band of gray matter appearance beneath the left cerebral cortex (possible band heterotopia).

The 3 patients with bilateral perisylvian and central involvement presented the features of the bilateral perisylvian syndrome as described by Kuzniecky et al. ${ }^{28-30}$ Imaging showed thickened cortex around the sylvian fissure, extending upward almost to the vertex in one and for some distance forward and backward in all three. Oropharyngeal dyspraxia, drooling and major phonatory difficulties were prominent. The facial appearance was remarkable with a lack of voluntary mimic but preservation of affectively induced movements. The three patients were severely retarded and had partial and secondary generalized seizures. Their EEGs showed only some slowing over the central areas of the scalp and focal spiking.

A majority of the 20 patients with unilateral focal dysplasia were referred because of refractory seizures. MRI showed areas of thickened cortex (Figure 5), often with an indistinct separation from the underlying white matter. In some cases, the area of abnormal cortex was extensive, involving the larger part of an hemisphere while in others it was hard to recognize. In 4 patients, there was deep infolding of the cortical plate into the white matter, almost reaching the ventricle, from which it remained separated by a thin layer of myelinated substance, which distinguishes such cases from those of schizencephaly. Recognition of small dysplastic areas was facilitated by the presence of abnormally intense signal on T2-weighted sequences and, in two cases, by the presence of a subcortical calcification on CT. The diagnosis of cortical dysplasia was confirmed pathologically in 6 cases. Pathological findings included disorganization of the cortical plate, heterotopic neurons and in two cases the presence of abnormal "balloon" cells. The epileptic attacks of these patients were partial complex seizures in all cases, but 2 patients also had simple partial (motor) seizures and one had partial continuous epilepsy. The origin of the seizures was thought to be in the temporal lobe in 9 cases, in the frontal lobe in 4 cases, and in the parieto-occipital region in 3 patients, on the basis of clinical features, interictal EEG data, and operative findings in 6 children. Eight patients had focal neurological signs in the form of hemiplegia or hemiparesis but
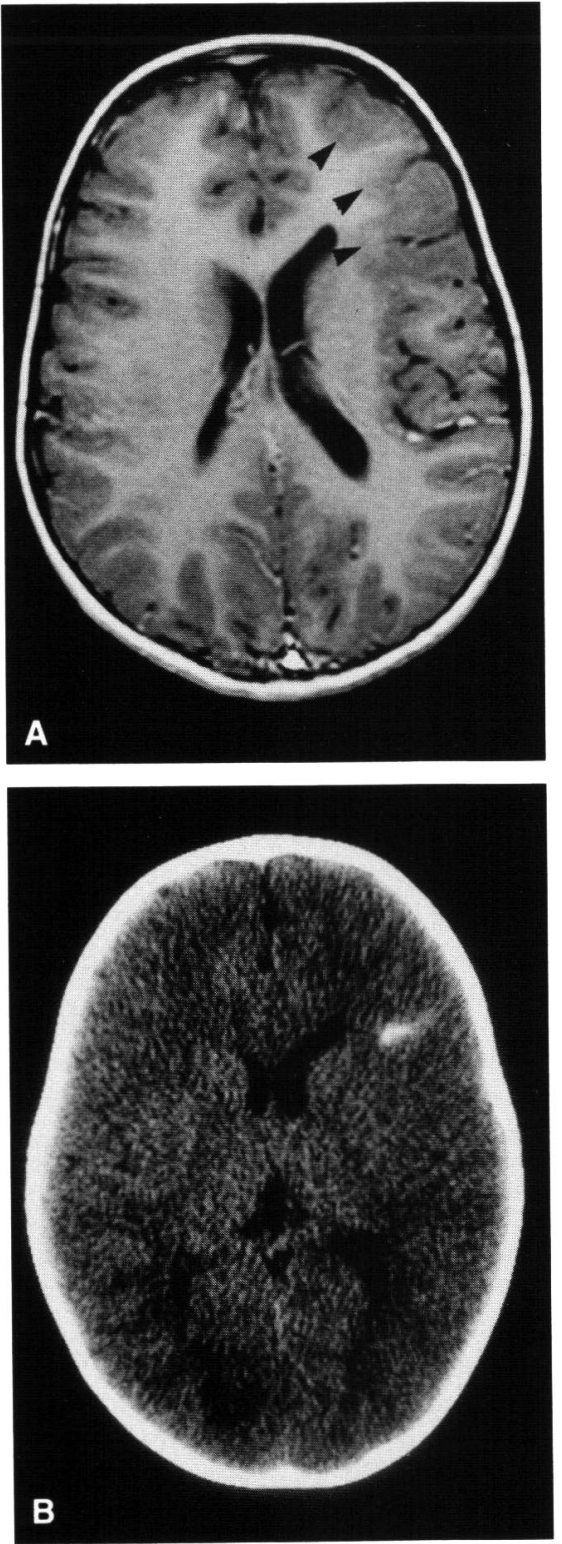

Figure 5: Focal cortical dysplasia; a) $T 1$-weighted $M R$, axial cut; b) $C T$ scan axial cut at same level. An area of thick, abnormal cortex is visible in the anterior left frontal lobe (arrowheads). On CT, there is a calcification in the underlying white matter. On T2-weighted $M R$ an abnormally intense signal was seen in the same area (not shown). The presence of such white matter abnormalities suggests that the dysplasia was secondary to an inflammatory or vascular process with gliosis and necrosis, probably acquired at a late stage of intrauterine life (26 weeks or more).

these were very mild in 4 of them. Twelve children were either mentally retarded or had severe learning difficulties while 8 patients had no cognitive problems. The EEGs of all 16 patients with epilepsy showed paroxysmal changes in the form of spikes usually appearing on an abnormally slow background rhythm. Both the slow waves and the spikes were localized to a restricted scalp area in 10 patients. In 6 other children, the paroxysmal activity was more diffuse with bilateral synchronous or asynchronous spiking over both hemispheres. Low amplitude fast rhythms were recorded over the abnormal cortex in four children. 
The high proportion of patients with isolated epilepsy in this series may reflect the preferential referral of such cases to a specialized epilepsy center.

\section{The Diagnosis of Neuronal Migration Disorders}

Neuronal migration disorders present with a spectrum of clinical manifestations of low specificity with, at one end, infants with severe neurological anomalies and massive developmental delay and, at the other end, children or adolescents with isolated partial epilepsy. Epilepsy, motor problems and mental retardation can exist in isolation or be variously combined. Epilepsies associated with migration defects are usually severe and resistant to therapy ${ }^{4,6,31-33}$ and tonic seizures, drop attacks, infantile spasms and the Lennox-Gastaut syndrome $e^{30,33,34}$ are especially apt to be observed. However, not all epilepsies associated with cortical malformations need be refractory to treatment and all types of seizures may be observed. ${ }^{31,33}$ Even typical rolandic seizures have been reported in this situation. ${ }^{35}$

Although epilepsy is the most common manifestation of neuronal migration disorders, it is by no means constant, even in the most diffuse and severe forms. In Dobyns series of 65 patients with agyria-pachygyria, $76 \%$ only had seizures. In the mildest forms, some patients may remain asymptomatic up to adulthood and it is indeed probable that some cases of migration abnormalities remain asymptomatic throughout life.

Similarly, the motor and mental manifestations of migration defects are quite variable from mild learning difficulties to profound idiocy and from mild hemiparesis to atonic diplegia. ${ }^{24,36}$ The only feature common to these manifestations is their static character so the possibility of cortical anomalies has to be considered in cases of cerebral palsy.

The frequency of neuronal migration abnormalities as a cause of the various clinical manifestations is not known. Cortical malformations have been found in 10 of 29 term infants with cerebral palsy studied on MRI by Truwit et al. ${ }^{37}$ Wilkund et al. ${ }^{38}$ observed anomalies of neuronal migration on CT in $16 \%$ of their cases of congenital hemiplegia and Koeda et al. ${ }^{39}$ found two of seven term infants with spastic diplegia had brain malformations on MR. Obviously, if there is a relationship between the extent of cortical abnormalities and the intensity of clinical manifestations, no clinical feature is characteristic of one particular type. However, certain clinical presentations are suggestive. The presence of a congenital pseudobulbar syndrome of the type initially reported by Worster-Drought ${ }^{40}$ in association with drop attacks and/or tonic seizures or a fullfledged Lennox-Gastaut syndrome ${ }^{30,33}$ indicates the likelihood of bilateral central and opercular dysplasia. Likewise, specific dysmorphic features and cortical myoclonus suggest the possibility of rolandic macrogyria ${ }^{41}$ or are indicative of Miller-Dieker syndrome ${ }^{23.24}$ or of Zellweger syndrome ${ }^{5}$ and cutaneous abnormalities, such as linear nevus or the Klippel-Trenaunay syndrome, are suggestive of hemimegalencephaly. ${ }^{42}$ The association of arthrogryposis with mental retardation is probably an argument in favor of developmental cortical abnormalities.

Finally, the clinical picture of the Walker-Warburg syndrome is quite distinctive and the association of congenital hydrocephalus, severe neurological dysfunction and eye abnormalities in association with vermal agenesis and a smooth cortex does not leave much room for other diagnoses.
The EEG can be of considerable help for the diagnosis of some of the diffuse migration disorders. In our series and in that of de Rijk van Andel ${ }^{43}$ as in those of Gastaut et al.$^{36}$ and Dulac et al. ${ }^{44}$ high amplitude fast activity was the most frequent finding in children with agyria-like or pachygyria-like imaging abnormalities. Quirk et al., ${ }^{45}$ however, found the theta-delta pattern, that they termed high amplitude rhythmic activity pattern, to be more common, as it was present in $47 \%$ of their 30 cases of agyria-pachygyria as against $30 \%$ for the fast pattern. Moreover, they thought the theta-delta pattern was highly specific for gyration anomalies whereas the fast pattern was found in many other types of structural brain abnormalities. They further indicated that low amplitude fast activity was more likely to suggest a structural abnormality than cortical dysplasia but that the converse was not true. The latter point is in contradistinction to the experience of others who believe that high amplitude fast rhythms are relatively specific in infants. ${ }^{24,36}$ All investigators agree that both suggestive EEG patterns may be absent in $20-30 \%$ of the cases of agyria-pachygyria more frequently in pachygyria.

Other less suggestive EEG abnormalities are found with multifocal or focal dysplasias. Spikes and slow spike-wave complexes may be limited to the abnormal area involved but may also occur bilaterally and symmetrically in some patients with localized lesions. ${ }^{31,33}$ Such diffusion, probably due to secondary bilateral synchrony, may have prognostic significance, heralding resistance to treatment and an overall unfavorable course. It may also be a predictor of poor surgical results as it seems to be associated with large, poorly limited dysplasias. ${ }^{33}$

The ultimate diagnostic tool is imaging and especially MRI. ${ }^{2.11}$ However, ultrasonography can demonstrate some diffuse migration defects such as lissencephaly but it does not permit prenatal diagnosis before the 30th week of gestation because of the late appearance of tertiary sulci.

In most cases, especially with diffuse dysplasias, the diagnosis of cortical migration abnormality is easy but the exact type is more difficult to define. In many patients, there is more than one type of lesion. For example, in Dobyns' series of 65 patients with apparent agyria, 12 had areas of possible or probable polymicrogyria as shown by undulations of the cortical surface and/or the white-gray interface. ${ }^{6}$ Even apparently typical agyria-like or especially pachygyria-like dysplasias may be shown by pathological study to be due to polymicrogyria as was the case in two patients with bilateral central pachygyria-like abnormalities ${ }^{34,36}$ and in a patient with unilateral focal dysplasia. ${ }^{33}$ It is also possible that the cases of agyria/pachygyria attributed to prenatal cytomegalovirus infections on the basis of imaging features ${ }^{47.49}$ were in fact cases of polymicrogyria. It is well established that polymicrogyria is the common type of migration abnormality found pathologically in cases of CMV infection..$^{50}$ Cases of agyria/pachygyria with calcification of the brain are not rare. Because calcifications are indicative of late brain insult ${ }^{8}$ it is unlikely that their cause could have interfered with the early process of migration that is completed by 20 weeks gestational age. ${ }^{1-3}$ Agyria is usually thought to represent migrational arrest before the 13th gestational week. ${ }^{23}$ On the contrary, polymicrogyria at least the classical 4-layer form ${ }^{9,24}$ is probably the result of a late post-migrational event producing laminar destruction of the 4 th and 5 th cortical layers, ${ }^{6,10,24}$ and its association with calcifications would be easily understandable. 
Similarly, the presence of imaging abnormalities in the white matter in the form of areas of high T2 signal underlying localized areas of cortical dysplasia would be more consistent with a late post-migrational process such as polymicrogyria than with an early event such as agyria. This is because such imaging abnormalities are probably the expression of glial scars and these do not form before the second half of gestational life. ${ }^{8}$

The type and extent of cortical abnormalities found by imaging have obvious prognostic implications. There is a rough inverse correlation between the number of sulci and the degree of disability in patients with agyria ${ }^{21,22}$ and most patients with pachygyria fare better than those with an agyric cortex.

In focal dysplasias, Guerrini et al. ${ }^{33}$ separated two types of localized migration abnormality on the basis of different imaging data. In the first type, the dysplastic areas were of large size and poorly limited. In the second, there was deep infolding of the cortex in a restricted area cortex. The first type, in their experience, was associated with generalized seizures, bilateral EEG abnormalities and a poor outlook. In the second, the seizures and EEG anomalies were focal and the prognosis was better. However, in our experience, there was no clear difference in electroclinical features and outlook between the two types of lesion. Barkovich indicated that infolding cortex may be suggestive of polymicrogyria ${ }^{51}$ whereas in the one patient studied pathologically by Guerrini et al. ${ }^{33}$ a classic cortical dysplasia with abnormal cells and disorganized cortex was found rather than polymicrogyric cortex. There is thus, no correlation between imaging and pathology in the localized migration defects.

In some cases of localized dysplasia, the diagnosis may be difficult and requires technically impeccable MR scans with sequences adequate to demonstrate optimally the cortical plate. In such cases, thin slices, various angles of cut and reformatting to permit precise assessment of suspicious areas may be necessary. Even with the best current techniques, however, a proportion of the cases of dysplasia do not show up on MR scans. New methods, such as study of fractal numbers of the gray-white interface may help to diagnose such cases..$^{52}$

\section{Etiological Factors}

A large majority of the cases of neuronal migration disorders occur sporadically and have no detectable cause.

Possible etiological factors include intrauterine infections, intrauterine circulatory disturbances, especially perfusion failure, and genetic factors including chromosomal anomalies and single gene mutations.

Intrauterine infections, in particular cytomegalovirus infection, are a significant cause of polymicrogyria. Associated abnormalities such as retinal lesions and especially periventicular calcifications are commonly present. At least 7 cases of apparent agyria-pachygyria probably due to CMV infection are on record ${ }^{47-49}$ but in none of these was the diagnosis confirmed by pathological examination. There are in addition several cases in which the presence of calcifications and/or other anomalies is suggestive of viral infection without laboratory confirmation. Whether some cases could be due to other viruses remains unknown. ${ }^{6}$ Gyration abnormalities in cases of viral infection may result from direct effect of the virus on sensitive cells or from perfusion failure accompanying the acute phase of intrauterine infection. ${ }^{54}$
Perfusion failure due to maternal bleeding, hypotension, toxemia or shock is also a possible cause of microgyria or other migration disorder. Norman ${ }^{54}$ described bilateral encephaloclastic lesions with polymicrogyria in a fetus aborted at 26 weeks following an episode of anoxia at 13 weeks. Barth ${ }^{55}$ thought that early insults could produce unlayered microgyria while later insult, after the 20th week could result in classical 4-layer microgyria. Agyria or pachygyria could conceivably also be due to early maternal adverse events. ${ }^{6}$ Polymicrogyria is commonly associated with schizencephaly whose cause is thought to be a destructive, possibly vascular insult. ${ }^{56}$

Four-layer polymicrogyria has been produced experimentally by cold-induced ischemic insult of the cortex before the end of neuronal migration. ${ }^{57,58}$ Evidence for perfusion failure or intrauterine infection in cases of cortical migration defects is mainly circumstantial. Dobyns ${ }^{6}$ found that $12 \%$ of the mothers of 65 children with agyria-pachygyria had bleeding early in pregnancy and another $12 \%$ gave a history of a flu-like illness.

Cytogenetic anomalies are present in probably all patients with Miller-Dieker syndrome ${ }^{6}$ either as a microscopic or as a submicroscopic deletion of chromosome 17 (17pl3.3 band). A similar submicroscopic deletion has also been found in cases of lissencephaly unassociated with the typical dysmorphism of Miller-Dieker syndrome. Dobyns $s^{6}$ found it in 6 of 44 studied cases. Interestingly 3 of his patients had incomplete lissencephaly with more sulci than patients with Miller-Dieker syndrome and 3 had pachygyria. None of those with deletions had brain calcifications, ventricular asymmetry, atrophy or images suggestive of polymicrogyric areas. Conversely, no patient with possible microgyric cortex had chromosomal abnormalities. Cases of $17 \mathrm{p} 13.3$ deletion were all sporadic. However, familial forms of the Miller-Dieker syndrome balanced translocation in a parent and an unbalanced deletion in more than one sib have been reported. ${ }^{25}$

Recently a gene responsible for the Miller-Dieker syndrome (LIS1) has been isolated. The gene product is a protein that presents several analogies to the cell-adhesion molecules. ${ }^{59}$

Familial cases of migration abnormalities are rather unusual except those of the Walker-Warburg syndrome with type 2 lissencephaly which are transmitted as an autosomal recessive character. ${ }^{24,60}$ In the present series, 2 probands with diffuse pachygyria-like abnomalities had 2 similarly affected sibs. Another proband had an affected apparently identical twin. The parents of these 6 children were consanguineous (first cousins in 1 couple, more distantly related in 2). Another male child with apparently complete agyria was born to a mildly retarded mother who had subcortical band heterotopia.

In Dobyns series of 65 cases, 5 of 62 siblings in 4 families were affected. ${ }^{6}$ All familial cases were atypical. Two probands with 2 sibs had neonatal microcephaly and died rapidly of respiratory insufficiency. One male proband with one affected sister also had microcephaly and areas of apparently microgyric cortex and a third male proband had 2 affected brothers, all with pachygyria-like images. Two siblings reported by Harbord et al. ${ }^{61}$ also had pachygyria and multiple classifications. There are, however, a few cases of familial agyria with pathological confirmation. Six male patients have been reported ${ }^{62,63}$ suggesting the possibility of X-linked inheritance.

Pinard et al. (personal communication 1993) have studied a remarkable family in which 2 female children of 2 different 
fathers born to a woman with subcortical band heterotopias had localized band heterotopias whereas one male child also of a different father had severe agyria/pachygyria-like changes. Such cases suggest the possible modifying role of the X-chromosome on the expressivity of a responsible dominant gene.

Localized migration abnormalities may also be familial. This is especially the case of the syndrome of bilateral perisylvian pachygyria-like anomalies that has been observed in siblings by Kuzniecky ${ }^{28}$ and Andermann. ${ }^{64}$

Genetic counselling for cortical migration abnormalities is currently difficult because of the obvious heterogeneity of the syndrome. Dobyns found an overall empirical risk of recurrence of $7 \%$ in one large series. ${ }^{6} \mathrm{He}$ put the risk to $25 \%$ in the case of infants with neonatal microcephaly and early death who probably represented a specific genetic syndrome with autosomal recessive inheritance. For infants with agyria/pachygyria-like imaging abnormalities, a high resolution caryotype should be obtained. If a 17p13.3 deletion is present, the risk for future pregnancies is probably nil when no translocation is found. If there is a translocation involving chromosome 17 a karyotype of the parents is necessary. Parents who are carriers of a translocation clearly have a high risk of recurrence. For families with a history of epilepsy and, especially, in the case of maternal mental retardation, however mild, a MRI scan of parents is mandatory to try to detect gyration anomalies especially subcortical laminar heterotopias. When these are present a risk of $50 \%$ is likely. Conversely, the risk of recurrence is very small or nonexistent in the case of infants with calcifications associated with neuronal migration disorders as well as in cases of gross hemispheral asymmetry and white matter anomalies. Familial cases with calcifications, however, have been reported. ${ }^{61} \mathrm{~A}$ low risk is likely in cases of polymicrogyria associated with schizencephaly although rare familial cases are on record. ${ }^{65-67}$

For probands with pachygyria-like abnormalities, a higher risk is possible as cases in siblings occur. It is not currently possible to separate cases of true pachygyria from those of polymicrogyria that may have a higher risk of recurrence.

\section{TreatMENT}

The treatment of neuronal migration abnormalities is currently limited to the therapy of epilepsy and to general supportive measures for disabled children.

Epilepsy due to cortical dysplasias is not necessarily intractable and a trial of medical treatment is always indicated and can be successful even in the case of severe and extensive lesions. Some authors ${ }^{34}$ believe that epilepsy itself may be as important as the extent and severity of the structural abnormalities for the occurrence and degree of mental retardation, as patients with similar lesions but severe epileptic syndromes (e.g., Lennox-Gastaut syndrome) do much worse than those with absent or mild epilepsy. In this view, vigorous treatment of severe epilepsy with conventional or novel antiepileptic drugs and/or with steroids or ACTH is warranted. Longitudinal callosotomy has been used with some success in diffuse or multifocal migration disorders such as laminar heterotopias ${ }^{27,32}$ and the bilateral perisylvian syndrome. ${ }^{28,34}$

Localized cortical dysplasias are amenable to resective surgery, provided it does not result in unacceptable deficits. The results are usually less favorable than those of resection of small indolent space-occupying lesions probably because lesions are quite extensive and their limits poorly defined so that only part of the abnormal tissue can be removed. Palmini et al. ${ }^{32}$ found that the best results were obtained when more than $50 \%$ of the abnormal area could be resected, irrespective of the extent of the epileptogenic area defined by electroencephalographic methods. However, only one of their 31 patients became seizure-free. Patients with focal dysplasias that could not be satisfactorily removed could benefit from palliative callosotomy.

\section{CONCLUSION}

Neuronal migration abnormalities play a considerable role as a cause of cerebral palsy, mental retardation and epilepsy. They appear to be one of the leading types of structural brain abnormalities of prenatal origin which are now thought to be the commonest etiology of non-progressive neurological disease in infancy and childhood. Cortical dysplasias are responsible for many cases of severe epilepsy and such cases may be amenable to surgical treatment when the location and extent of the lesion make their removal possible. Considerably more knowledge of their causes, mode of constitution and pathogenetic role is desirable and better diagnostic techniques that would permit recognition of currently undetectable lesions and improve delimitation of their extent are urgently needed.

\section{REFERENCES}

1. Rakic R. Cell migration and neuronal ectopias in the brain. Birth Defects 1975; 11: 95-129.

2. Barkovick AJ, Chuang SH, Norman D. MR of neuronal migration anomalies. Am J Neuroradiol 1987; 8: 1009-1017.

3. McConnell S. Perspectives in early brain development and the epilepsies. In: Engel J et al., eds. Molecular Neurobiology of Epilepsy, Amsterdam: Elsevier 1992: 183-191.

4. Dobyns WB, Elias ER, Newlin AC, Pagon RA, Ledbetter DH. Causal heterogeneity in isolated lissencephaly. Neurology 1991; 42: $1375-1388$.

5. Aicardi J. Diseases of the Nervous System in Childhood. London: MacKeith Press 1992: 150-172.

6. Dobyns WB. Developmental aspects of lissencephaly and the lissencephaly syndromes. Birth Defects 1993; 23: 225-241.

7. Sarnat HB. Disturbances of late neuronal migrations in the perinatal period. Am J Dis Child 1987; 141: 969-980.

8. Lyon G. Beaugerie A. Disturbances of neuronal migration. In: Levene MI et al., eds. Fetal and Neonatal Neurology and Neurosurgery. Edinburgh: Churchill Livingstone 1988: 231-248.

9. Williams RS, Caviness VS. Normal and abnormal development of the brain. In: Tarter RE, Goldstein J, eds. Advances in Clinical Neuropsychology. Vol. 2. New York: Plenum 1984: 1-62.

10. Stewart RM, Richman DP, Caviness VS. Lissencephaly and pachygyria: an architectonic and topographical analysis. Acta Neuropathol 1975; 31:1-12.

11. Titelbaum DS, Hayward JC, Zimmerman RA. Pachygyria-like changes: topographic appearance at MR imaging and CT and correlation with neurologic status. Radiology 1989; 173: 663667.

12. Meencke HJ, Janz D. Neuropathological findings in primary generalized epilepsy. A study of eight cases. Epilepsia 1984; 25: 8-21.

13. Meencke HJ, Veith J. Migration disturbances in epilepsy. In: Engel J et al., eds. Molecular Neurobiology of Epilepsy. Amsterdam: Elsevier 1992: 31-40.

14. Huttenlocher PR, Taravath S, Mojtahedi S. Periventricular heterotopia and epilepsy. Ann Neurol 1994; 44: $51-55$.

15. Kamuro K, Tenokuchi YI. Familial periventricular nodular heterotopia. Brain Dev 1993; 15: 237-241.

16. Della Giustina E, Goffinet AM, Landrieu P, Lyon G. A Golgi study of the brain malformation in Zellweger's cerebro-hepato-renal disease. Acta Neuropathol 1981; 55; 23-28. 
17. Böhm N, Uy J, Kiessling M, Lehnert W. Multiple acyl-CoA-dehydrogenase deficiency (glutaric aciduria type II), congenital polycystic kidneys and symmetric warty dysplasia of the cerebral cortex in two newborn brothers. II. Morphology and pathogenesis. Eur J Pediatr 1982; 139: 60-65.

18. Robain $\mathrm{O}$, Floquet $\mathrm{C}$, Heldt $\mathrm{N}$, Rozenberg $\mathrm{F}$. Hemimegalencephaly: a clinicopathological study of four cases. Neuropathol Appl Neurobiol 1988; 14: 125-135.

19. Chevrie JJ, Aicardi J. The Aicardi syndrome. In: Pedley TP, Meldrum BS, eds. Recent Advances in Epilepsy, vol. 3. Edinburgh: Churchill Livingstone 1986: 189-210.

20. Fukuyama $Y$, Osawa M, Suzuki H. Congenital progressive dystrophy of the Fukuyama type - clinical, genetic and pathological considereations. Brain Dev 1981; 3: 1-29.

21. Dobyns WB, McCluggage CW. Computed tomographic appearance of lissencephaly syndromes. Am J Neuroradiol 1985; 6: 545-550.

22. De Rijk van Andel JF, Arts WF, Barth PG, Loonen MC. Diagnostic features and clinical signs of 21 patients with lissencephaly type I. Dev Med Child Neurol 1990; 32: 707-717.

23. Dobyns WB, Greenberg F. Syndromes with lissencephaly. I. Miller-Dieker and Norman-Roberts syndromes and isolated lissencephaly. Am J Med Genet 1984; 18: 509-526.

24. Aicardi J. The agyria-pachygyria complex: a spectrum of cortical malformations. Brain Dev 1991; 13: 1-8.

25. Goutières F, Aicardi J, Rethoré MO, Lejeune J. Syndrome de Miller-Dieker et translocation chromosomique (15;17). Arch Franç Pédiatr 1987; 44: 501-504.

26. Livingston JH, Aicardi J. Unusual MRI appearance of diffuse subcortical heterotopia or "double-cortex" in two children. J Neurol Neurosurg Psychiatry 1990; 53: 617-620.

27. Palmini A, Andermann F, Aicardi J et al. Diffuse cortical dysplasia or the "double cortex" syndrome: the clinical and epileptic syndrome in 10 patients. Neurology 1991; 41: 1656-1662.

28. Kuzniecky R, Andermann F, Guerrini R et al. Congenital bilateral perisylvian syndrome: study of 31 patients. Lancet 1993; 341: 608-612.

29. Kuzniecky R, Andermann F, Tampieri D et al. Bilateral central macrogyria, epilepsy, pseudobulbar palsy, and mental retardation. A recognizable neuronal migration disorder. Ann Neurol 1989; 25: 547-554.

30. Guerrini R, Dravet C, Raybaud C et al. Neurological findings and seizure outcome in children with bilateral opercular microgyriclike changes detected by MRI. Dev Med Child Neurol 1992; 34: 694-705.

31. Palmini A, Andermann F, Olivier A et al. Focal neuronal migration disorder and intractable epilepsy: a study of 30 patients. Ann Neurol 1991; 30: 741-749.

32. Palmini A, Andermann F, Olivier A et al. Focal neuronal migration disorder and intractable epilepsy: results of surgical treatment. Ann Neurol 1991; 30: 750-757.

33. Guerrini R, Dravet C, Raynaud C. Epilepsy and focal anomalies detected by MRI: electroclinico-morphological correlations and follow-up. Dev Med Child Neurol 1992; 34: 706-718.

34. Palmini A, Andermann F, de Grissac $\mathrm{H}$ et al. Stages and patterns of centrifugal arrest of diffuse neuronal migration disorders. Dev Med Child Neurol 1993; 35: 331-339.

35. Ambrosetto G. Unilateral opercular macrogyria and benign childhood epilepsy with centrotemporal (rolandic) spikes: report of a case. Epilepsia 1992; 33: 499-503.

36. Gastaut $H$, Pinsard N, Raybaud C, Aicardi J, Zifkin B. Lissencephaly (agyria-pachygyria): clinical findings and serial EEG studies. Dev Med Child Neurol 1987; 29: 167-180.

37. Truwit CG, Barkovich AJ, Koch TK, Ferriero DM. Cerebral palsy: MR findings in 40 patients. Am J Neuroradiol 1992; 13: 67-78.

38. Wilkund LM, Uvebrandt P, Flodmark $O$. Morphology of cerebral lesions in children with congenital hemiplegia. Neuroradiol 1990; 32: 179-186.

39. Koeda T, Suganuma I, Kohno Y, Takamatsu T, Takeshita K. MR imaging of spastic diplegia. Neuroradiol 1990;32: 187-190.

40. Worster-Drought C. Suprabulbar paresis. Dev Med Child Neurol 1975; suppl.30:1.

41. Kuzniecky R, Berkovic S, Andermann F et al. Focal cortical myoclonus and rolandic cortical dysplasia: clarification by magnetic resonance imaging. Ann Neurol 1988; 23: 317-325.
42. Barkovich AJ, Chuang SA. Unilateral megalencephaly: correlation of MR imaging and pathologic characteritics. Am J Neuroradiol 1990; 11:523-531.

43. De Rijk van Andel JF, Arts WFM, de Weerd AW. EEG and evoked potentials in a series of 21 patients with lissencephaly type I. Neuropediatrics 1992; 23: 4-9.

44. Dulac O, Plouin P, Perulli $\mathrm{M}$ et al. Aspects électroencéphalographiques de l'agyrie-pachygyrie classique. Rev. Electroencephalogr Neurophysiol Clin 1983; 13: 232-239.

45. Quirk JA, Kendall B, Kinglsey DPE, Boyd S, Pitt MC. EEG features of cortical dysplasia in children. Neuropediatrics $1993 ; 24$ 193-199.

46. Becket PM, Dickson AM, Troncoso JC. Bilateral opercular polymicrogyria. Ann Neurol 1989; 25: 90-92.

47. Norman MG, Roberts M, Sirois J, Tremblay LJM. Lissencephaly. Can J Neurol Sci 1976; 3: 39-46.

48. Wayne ER, Burrington JD, Myers DN, Cotton C, Block W Bilateral eventration of the diaphragm in a neonate with congenital cytomegalic inclusion disease. J Pediatr 1973; 83: 164-165.

49. Hayward JC, Titelbaum DS, Clancy RR, Zimmerman RA Lissencephaly-pachygyria associated with congenital CMV infection. J Child Neurol 191; 6: 109-114.

50. Friede RL. Developmental Neuropathology, 2nd edn. Berlin: Springer 1989: 340-346

51. Barkovich AJ, Jos D. Nonlissencephalic cortical dysplasia. Correlation of imaging findings with clinical deficits. Am J Neuroradiol 1992; 13: 95-103.

52. Cook MJ, Free SL, Fish DR et al. Analysis of cortical patterns. In: Shorvon SD et al., eds. Magnetic Resonance and Epilepsy. London: Plenum (in press).

53. Marques-Dias MJ, Harmant-Van Rijckevorsel G, Landrieu P, Lyon G. Prenatal cytomegalovirus disease and cerebral microgyria: evidence for perfusion failure, not disturbance of histogenesis, as the major cause of fetal cytomegalovirus encephalopathy Neuropediatrics $1984 ; 15: 18-24$.

54. Norman MG. Encephaloclastic lesions in a 26-week gestation fetus: effect on neuronal migration. Can J Neurol Sci 1987; 14: $1-16$.

55. Barth PG. Disorders of neuronal migration. Can J Neurol Sci 1987 ; 14: 1-16.

56. Menezes L, Aicardi J, Goutières F. Absence of the septum pellucidum with porencephalia: a neuroradiologic syndrome with variable clinical expression. Arch Neurol 1988; 542-545.

57. Dvorak K, Feit J. Migration of neuroblasts through partial necrosis of the cerebral cortex in newborn rats. Contribution to the problem of morphological development and development period of cerebral microgyria. Acta Neuropathol 1977; 38: 203-21 2.

58. Dvorak K, Feit J, Jurankova Z. Experimentally induced focal microgyria and status verrucosus deformis in rats: autoradiographical study. Acta Neuropathol 1978; 44: 121-129.

59. Reiner O, Carozzo R, Shen Y. Isolation of a Miller-Dieker lissencephaly gene containing G-protein beta subunit-like repeats. Nature 1993.

60. Bordarier C, Aicardi J, Goutières F. Congenital hydrocephalus and eye abnormalities with severe developmental brain defects: Warburg syndrome. Ann Neurol 1984; 16: 60-65.

61. Harbord MG, Boyd S, Hall-Crags et al. Ataxia, developmental delay and an extensive migration abnormality in 2 siblings. Neuropediatrics 1990; 21: 218-221.

62. Parkind H, Sotne TT. Familial spastic paralysis: report of three cases in one family and observation at necropsy. Arch Neurol Psychiatry 1933; 30: 481-500.

63. Pavone L, Gulotta F, Incorpora G, Grasso S, Dobyns WB. Isolated lissencephaly: report of four patients from two unrelated families. J Child Neurol 1990; 5: 52-59.

64. Andermann E, Palmini A, Andermann $F$ et al. Familial bilateral congenital perisylvian syndrome: genetic determination of a localized neuronal migration disorder. Neurology 1992; 42 (suppl. 3): 354A.

65. Hosley MA, Abroms IF, Ragland RL. Schizencephaly: case report of familial incidence. Pediatr Neurol 1992; 8: 148-150.

66. Robinson RO. Familial schizencephaly. Dev Med Child Neurol 1991; 33: 1010-1014.

67. Hilburger AC, Willis JK, Bouldin E, Henderson-Tilton A. Familial schizencephaly. Brain Dev 1993; 15: 234-236. 